\title{
SOCIAL INSTITUTIONS AND SANCTIONED BEHAVIORS: A CROSS-NATIONAL STUDY*
}

\author{
K. Praveen Parboteeah, ${ }^{*}$ Martin Hoegl, ${ }^{* *}$ and John B. Cullen ${ }^{* * *}$
}

\begin{abstract}
This research considers important social institutions (e.g., the economic system, the level of industrialization, the level of social inequality, and the degree of religiosity) as determinants of individuals' justifications to commit socially sanctioned behaviors. Using factor analyses on data from 32,734 individuals located in 27 nations, we find that regardless of country, all individuals group 23 socially sanctioned behaviors uniformly in three categories, which we term controversial behaviors (e.g., abortion), peccadilloes (e.g., keeping money found), and illegal behaviors (e.g., political assassinations). We used Hierarchical Linear Modeling (HLM) to test the country-level effects of the social institutions on individuals' ability to justify these three types of sanctioned behaviors. The results confirm that the social institutions influence individuals' justifications of sanctioned behaviors, above and beyond important individual-level control variables included in the HLM analyses. The economic system (degree of socialism) and the level of industrialization show positive effects on all three types of sanctioned behaviors. Social inequality has a positive effect on illegal behaviors and peccadilloes, but a negative effect on controversial behaviors. Religiosity affects illegal behaviors positively and controversial behaviors negatively with no significant influence on peccadilloes.
\end{abstract}

* Management Department, College of Business \& Economics, 800 West Main Street, University of Wisconsin-Whitewater, Whitewater, WI 53190, USA, (parbotek@mail.uww.edu).

** Institute of Organization and Information Systems, Bocconi University, Viale Isonzo 23, 20135 Milano, Italy, (hoegl@yahoo.com).

*** Management Department, Washington State University, Pullman, WA 99164-4736, USA, (cullenj@wsu.edu).

An earlier version of this paper was presented at the 2001 Academy of Management Meetings in Washington, D.C,Thursday, April 15, 2004.

The authors thank the ICPSR for making the data available.

(C) de Sitter Publications

IJCS 2003 44(3):239-265 
Sociologists and psychologists alike continue to be intrigued by perpetrators of behaviors that are counter to conventional social norms or expectations (e.g., Goodwin and Goodwin 1999; Osgood et al. 1996; Vieraitis 2000; and Wood 2000). Such behaviors, which we term as sanctioned behaviors, range from behaviors that elicit disapproval or shunning from other members of society (i.e., controversial behaviors such as divorce, suicide, and abortion) to behaviors heavily punished by societal institutions (i.e., illegal behaviors such as buying stolen goods and assassinating people).

Reviews of the extant literature on sanctioned behaviors in an international context reveal some gaps. Firstly, most research on controversial behaviors, primarily undertaken by psychologists, emphasizes individual factors while cross-national studies rely primarily on Hofstede's (1980) national culture dimensions or social institutions. Secondly, most research on illegal behaviors concentrates on explanations of U.S. illegal behaviors. However, with globalization of trade, it is becoming increasingly important to understand sanctioned behaviors in other societies. Finally, despite considerable progress in research on both controversial and illegal behaviors, both streams of research seem to have operated separately.

Given the above noted shortcomings, we contribute to the literature by examining how selected social institutions affect 32,734 individuals' (located in 27 nations) justifications of both controversial and illegal behaviors. We extend the literature in several ways. First, rather than dichotomizing the literature in controversial and illegal behaviors, we consider them within the same categorization but with differences in degree of seriousness of sanctions. Although this approach seems unusual, it can nevertheless provide the necessary cross-disciplinary focus to assess disparate progress in both literatures. We provide convergence by examining the impact of country-level social institutional variables on individuals' intentions through psychological explanations of how social institutions affect individuals. Second, we develop the rudiments of a theory based on social institutions that explains why individuals located in different nations justify controversial and illegal behaviors. Such an endeavor is necessary because most research 
thus far on these behaviors rely exclusively on the United States. However, with globalization, it is necessary to understand how social institutions work to influence individual controversial and illegal behavior on a cross-national level. Thirdly, we also extend the literature on illegal behaviors by considering more distal but important factors, rather than the more typical individual level (i.e., personal histories of offenders) or societal level factors (i.e., dependence of illegal behaviors on opportunities presented by routine activities of daily life). As such, we also contribute to a more complete theory of tolerance for illegal behaviors by incorporating country-level situational factors. Finally, although we do not examine actual behaviors, we nevertheless focus on individuals' justification of socially sanctioned behaviors rather than the more typical reliance on collective measures such as crime rate.

\section{SOCIAL INSTITUTIONS, CONTROVERSIAL AND ILLEGAL BEHAVIORS}

Social institutions are defined as "a complex of positions, roles, norms, and values lodged in particular types of social structures and organizing relatively stable patterns of human resources with respect to fundamental problems in...sustaining viable societal structures within a given environment" (Turner 1997:6). In the context of this study, we focus on four established and important social institutions: the economic system, social inequality, the level of industrialization, and religion.

Social institutions present a freedom/constraint duality (Fararo and Skovretz 1986). They are "frameworks of programs or rules establishing identities and activity scripts for such identities" (Jepperson 1991:146). Social institutions affect individual behaviors by providing "programmed actions" (Berger and Luckmann 1967:75) or "common responses to situations" (Mead 1972:263) that provide individuals with appropriate behaviors when facing ethical or legal situations. Institutions have structures that embrace values or standards of good/bad, appropriate/inappropriate, worthy/unworthy against which individuals' roles are evaluated. By influencing behaviors through constraints, we expect social institu- 
tions to provide the necessary schema or script that help individuals assess justifications of sanctioned behaviors. In sum, as individuals are faced with potential sanctioned behaviors, they will rely on the constraints placed by social institutions to assess such behaviors.

However, the very nature of social institutions that produce values or standards of good and bad can also encourage justifications of sanctioned behaviors. By promoting ideals and proposing values and beliefs, social institutions can implicitly promote certain sanctioned behaviors. For example, the nature of the U.S. capitalist system where the reaching of any end is characterized by a "any means necessary" philosophy can actually encourage sanctioned behaviors as the most efficient means to achieve those ends (Messner and Rosenfeld 1994). As such, although social institutions provide constraints, they also provide choices within constraints. We adopt the assumption of the choice-within-constraints new institutionalism (Ingram and Clay 2000) that individuals make choices that further their interests within their limited capacity to retain and process information, for instance, bounded rationality (Simon 1957).

The following considers four prominent social institutions and the likely link with justifications to commit controversial and illegal behaviors. Our hypotheses are based on the assumption that cultures have the same value set (e.g., Kohlberg's (1984) universalism) but that social institutions and the cultural surroundings affect people's justifications to commit sanctioned behaviors. Although the question is an issue of contention among researchers, there is nevertheless some evidence to support this position (Diamond 1982; Robertson and Fadil 1999).

\section{The Economic System}

The government is, of all social institutions, the one that has special powers and prerogatives, with the "ability to rely on legitimate coercion" (Streeck and Schmitter 1985:20). Recent research provides evidence that the role of the state is strengthening (Knutsen 1995; Van Deth 1995). Thus, understanding the impact of the governments is even more critical given the increased importance of the role of 
the government in the economic, social, and cultural arenas of most societies (Van Deth 1995).

The government typically fulfills two major roles in the economy including economic coordination and the appropriation and redistribution of economic wealth (Knutsen 1995; Turner 1997). Often, when governments intervene minimally, ownership is left to the private sector. This minimal state intervention represents the capitalist model where control of major economic resources is delegated to private owners and their agents (Whitley 1994). In contrast, when governments intervene more actively, it represents the contemporary socialist economic system (Marx 1936), varying between the centralized planning of the communist system and the redistributive welfare of the Western social democracies (EspingAnderson 1990).

The economic systems have undeniable potential effects on justifications of sanctioned behaviors. In capitalist systems, individuals are faced with various situations that may encourage justifications of sanctioned behaviors as a means to cope with life. Capitalism has been described as a "self-serving economic system where everyone looks out primarily for his/her own interests" (Ralston et al. 1997), which most likely encourages materialism (Chiu et al. 1998; Messner and Rosenfeld 1994). This social validation of self-serving and materialistic characteristics in itself is very likely to encourage justifying sanctioned behaviors. Because behaving in one's own interest is acceptable but can potentially mean harming the greater good and breaking social norms, individuals in capitalist societies seem more likely to justify sanctioned behaviors. In addition, in capitalist countries, individuals are extremely vulnerable to powerful corporations and other fluctuations in the economy (Olsen 1991). Individuals do not have job or security guarantees typical of socialist economies. They can be fired at will, are not provided with social services, and are expected to provide for themselves. Such challenges inevitably produce anxieties and frustrations where individuals may resort to justifications of suicide (controversial behavior) or theft (illegal behavior) to cope with daily life. In sum, in political terms, a capitalist society implies a relatively weak state, strong resistance against government regulation, and oppositions to notions of social and economic equality 
(Knutsen 1995). Thus, we expect this laissez-faire attitude to act as catalysts for justifications of sanctioned behaviors.

In contrast, socialistic philosophy teaches that the good of all is everyone's concern (Ralston et al. 1997). In socialist systems, the state has a key role in economic distribution, protecting, and providing for employees (Knutsen 1995; Rossides 1990). The socialist state provides security guarantees such as jobs, social assistance programs, and even deliberate destratification approaches to reduce income differences among social groups (Parish 1984). Such policies provide for security guarantees that are less likely to encourage justifications of sanctioned behaviors. In addition, provision of economic rewards are not limited to income, but may also take the form of redistributive benefits such as health care, welfare programs, and housing that depend on the workplace (Walder 1992). The surplus thus generated by workers in a socialist state is to provide for societal needs, not for profit, as is the case in a capitalist society (Warhurst 1998).

Given the above, it is plausible to argue that capitalist societies create conditions where the likelihood that individuals' justifying of illegal and controversial behaviors is enhanced. However, the social guarantees and securities provided by a socialist economy are more likely to discourage and take a more active role in punishing sanctioned behaviors.

HYPOTHESIS 1: Individuals in more socialist societies are less likely to justify sanctioned behaviors.

\section{Industrialization}

Industrialization and the level of economic development have had a very critical impact on the organization of societies. The application of the steam engine to production initiated massive structural changes resulting in the European industrial revolution (Turner 1997), which then spread to other parts of the world. As such, industrialization has created major changes in most societies.

Industrialization produces several changes in society that are likely to affect justifications to commit sanctioned behaviors. Blau and Duncan (1967) argue that, as countries industrialize, there is a 
value change towards universalism. With universalism, selection for occupational positions is based more on achievement than ascription (social background or family). As the basis for occupational roles shifts from ascriptive to universalistic achievement criteria, individuals may become more hard working and ambitious, given that they can climb the social ladder through achievements. However, as is the case in many industrialized nations, such ambition and hard work can also lead to an imbalance in life whereby work is emphasized at the expense of other life areas such as leisure, family, and friends. Such imbalance can produce frustration, anxieties and other ills, which individuals may cope with by justifying sanctioned behaviors. For example, if individuals cannot cope with life because of pressures of work, they can justify petty venting mechanisms (i.e., smoking marijuana and joyriding) to extreme sanctioned behaviors (i.e., suicide, drinking and driving).

Industrialization also means that work is broken down into smaller and smaller component tasks and specific domains of knowledge are applied to each of these small tasks (Baba 1995), promoting a cold and efficient rationalization of production (Smits Ultee; Lammers 1997). As technology becomes a substitute for labor, there is tension and conflict between the two (Braverman 1974). Given the general importance of work to individuals' lives, this loss of work meaning can also enhance sanctioned behaviors. As individuals lose their work identities, they may justify breaking social norms and sanctioned behaviors as a means to cope with life realities.

Industrialization, with its emphasis on work (Kerr, Harbison, Dunlop, and Myers 1996), also means that the role of the family is decreasing. A decreased role of the family means that the socialization role of the family is also lessened. As such, if the critical role of education in social norms is de-emphasized, it seems plausible to argue that more individuals are likely to justify behaviors counter to social norms. In addition, the prevalence of nuclear families also implies the marked absence of authority figures, someone whose responsibility is to attempt social control to prevent deviance (Osgood et al. 1996). Such absences can also encourage intentions to commit illegal behaviors. 
In contrast, individuals in less industrialized nations may feel that they have less control over their lives because status is ascribed to them. Also, with the absence of pressures to achieve, typical in more industrialized nations, there may be less pressure to justify illegal behaviors. Also, the more predominant role of the family may provide the necessary social education to discourage controversial behaviors. Finally, the more fatalistic nature of less industrialized societies may prevent higher justification of undesirable behaviors.

HYPOTHESIS 2: Individuals in more industrialized nations are more likely to justify sanctioned behaviors.

\section{Social Inequality}

Social inequality refers to the process by which "social benefits are unequally distributed and those patterns of organized inequality are perpetuated through time" (Olsen 1991:375). Although social inequality has been part of humankind for centuries, individuals seldom have the power to question its existence. Lewis (1978) argues that the various socialization agents (schools and parents) teach children from all class levels a culture of inequality that justifies and supports social stratification.

The societal effects of social inequality on sanctioned behaviors, and specifically, illegal behaviors and crime has received extensive attention in the literature (see Vieraitis (2000) for a list of such studies). Although various theoretical perspectives have been used to explain the likely link between social inequality and sanctioned behaviors (e.g., Blau and Blau 1982; Merton 1938), we use equity theory (Adams 1965), and argue that disadvantaged or underprivileged individuals in societies with higher social inequalities will have a higher desire to achieve fairness. Whether they want to strive for equity or equality, undesirable behaviors provide a means through which imbalances can be reduced. Hence, we posit that the large numbers of disadvantaged individuals in societies with high social inequalities may justify sanctioned behaviors as a means of dealing with social injustices. In such cases, the under- 
privileged individuals may perceive illegal behaviors such as cheating on taxes or accepting bribes as justified responses given the unfairness of the overall distribution of opportunity in their society. Furthermore, disadvantaged members of societies with high social inequalities have less at risk when committing controversial behaviors such as abortion, divorce, or admitting to homosexuality. The perceived inability to rise to higher social classes or experience and utilize opportunity may result in a "nothing-to-lose" attitude of underprivileged individuals. Similarly, the privileged members of society may feel that there is little risk of losing social status if they committed controversial behaviors such as having an affair or terminating a pregnancy. These arguments are consistent with Becker's (1968) economic crime model where the benefits of the sanctioned behaviors for both disadvantaged and privileged members outweigh the expected costs of the behaviors. Hence, the perceived stability of the social order creates a context conducive to controversial behaviors, as social sanctions tend to provide a less effective deterrent.

In contrast, societies with less social inequality have more individuals that are afforded opportunities to succeed (Kohn et al. 1997) which reduces the probability that individuals rationalize their sanctioned behaviors on grounds of social inequality or justify controversial behaviors on the basis of a more fatalistic mindset.

HYPOTHESIS 3: Individuals in countries with higher social inequality are more likely to justify sanctioned behaviors.

\section{Religion}

Religions are important social institutions in most societies. Religious values often build the basis for what is considered right and wrong, proper and improper (Turner 1997). Such values and beliefs are often codified into religious writing such as the Bible or the Koran. In Christian religions, for instance, the ten commandments provide a broad basis of codified ethical rules that believing Christians must follow in order to actualize what they belief in, for example, eternal life after death (salvation). In societies where one or few religions are dominant, the overarching core values of these 
religions are likely to be mirrored in secular values of society (codified law or non-codified social norms), which regulate everyday activity.

The classic work of Max Weber (1922) on the sociology of religions (Religionssoziologie) investigating the influence of religion on the development of capitalism highlights, among other things, the protestant work ethic as a major driver of capitalism in the nineteenth century. Weber considered the ascetic nature of the protestant work ethic to be quite similar to that of catholic monks. For some protestant denominations (e.g., Calvinists, Quakers, and Mennonites), Weber identifies the combination of an ascetic bibledriven life style with a pronounced "spirit of work and enterprise" (Geist der Arbeit) that fostered economic development while closely observing the values and regulations reinforced by the religion. This example underlines the role that religions (in general) still play in seemingly ever more secular societies.

Recognizing that Weber's work focused on the spread of capitalism in the nineteenth century rather than individual conduct today, we do not advocate to distinguish among religions in explaining justifications of illegal and controversial behavior of individuals across different societies. Building on the notion of universalism of values (Kohlberg 1984), we assume that the main world religions as values-shaping social institutions are comparable in that they promote sanctioning of similar behaviors (e.g., stealing, lying, divorce, and prostitution). Thus, for the purpose of this discussion it is less relevant which religion is dominant in any given society, but whether individuals are influenced on a spiritual level by their religion. We argue that the religiosity of society (i.e., the social influence of one or several religions) provides individuals with additional guidance in regard to their behavior. Hence, a lack of a religiosity leaves individuals with less direction regarding desired or expected courses of action. This may be particularly important for controversial issues outside the regulatory framework of applicable laws (e.g., abortion and suicide). Moreover, prominent religions, serving as strong social institutions, may also reinforce laws that often embody religious principles thereby reducing the probability to justifications illegal behaviors. 
HYPOTHESIS 4: Individuals in countries where religion plays a prominent role are less likely to justify sanctioned behaviors.

\section{METHODS}

\section{Sample}

The universe for the survey included adults 18 and over in 27 countries. Both national random and quota sampling were used. The result was a data set that included individual-level data on 32,734 individuals and social institutional data on 27 countries. The Appendix shows the countries studied and their respective sample size.

\section{Dependent Variables}

Individual-level data on peoples' justification of committing controversial or illegal behaviors came from World Values Survey (World Values Study Group 1994), which was made available through the Inter-University Consortium for Political and Social Research. All surveys were conducted with face-to-face interviews.

To measure justification of socially sanctioned behaviors, respondents were presented with actions such as "political assassinations," "taking marijuana or hashish," "fighting with the police," and "prostitution" and asked the extent to which these behaviors are justified (on a scale from 1 to 10). In total, the World Values Survey includes twenty-four items pertaining to controversial and illegal behaviors of individuals. Such behaviors include generally legal but controversial behaviors such as abortion, divorce, and suicide, as well as more serious legal offenses including accepting bribes, buying stolen goods, and drunk driving.

In order to establish measures of individuals' justification of committing controversial and illegal behaviors, we conducted a series of exploratory and confirmatory factor analyses on these data. In doing so, possible dependencies of observations within one country needed to be dealt with. To control for such country-effects 
we have regressed country on all twenty-four behavior items and saved the standardized residuals for further analyses. We used the standardized residuals from this procedure ("purified" from country-effects) as input for the subsequent factor analyses including all 32,734 individual-level responses.

An exploratory factor analysis including all twenty-four items resulted in three factors being extracted (with eigenvalues greater than 1). Analyzing the rotated component matrix (Varimax rotation method), only one item (killing in self-defense) was excluded from further analyses as it failed to show a loading greater than .40 on any of the three extracted factors. The factor loadings reported in Table 1 illustrate a clear division of these twenty-three items in three blocks. The first factor includes eight indicators that pertain to matters largely viewed as contentious in societies including abortion, divorce, homosexuality, and suicide. We see this factor as corresponding to what we have earlier termed controversial behaviors. Respondents providing a high rating on those indicators may be described as more open and tolerant to individual personal choices in matters that were often historically regulated by social institutions such religion or legal systems. The second factor includes ten indicators highlighting clearly deviant behaviors (i.e., illegal acts). These indicators include drunk driving, purchase of stolen goods, and accepting bribes. We see this factor as directly relating to what we term illegal behaviors. The third factor consists of five items that refer to what may be perceived by many as less serious legal offenses such as cheating on taxes, lying in one's own interest, and avoiding public transportation fees. We term this category of justifications of behaviors as peccadilloes.

We conducted confirmatory factor analyses as well as reliability analyses on all three measures to test internal consistency. The factor analyses resulted in one-factor solutions for each of the three constructs with all items loading well above .50. All three constructs showed acceptable to strong reliability with a Cronbach's alpha coefficient of .82 for controversial behaviors, .78 for illegal behaviors, and .67 for peccadilloes. Provided the demonstrated discriminant and convergent validity of the three measure, we have aggregated the respective items by calculating the arithmetic means for the three constructs. 
Table 1. Factor Analysis Results of Individuals' Justification of Socially Sanctioned Behavior

\begin{tabular}{|c|c|c|c|}
\hline $\begin{array}{l}\text { Please tell me for the following statements } \\
\text { whether you think it can be justified ( } 10 \text { pts } \\
\text { scale) }\end{array}$ & $\begin{array}{l}\text { Peccadilloes } \\
(\alpha=0.67)\end{array}$ & $\begin{array}{l}\text { Illegal } \\
\text { behavior } \\
(\alpha=0.78)\end{array}$ & $\begin{array}{l}\text { Controversial } \\
\text { behavior } \\
(\alpha=0.82)\end{array}$ \\
\hline Keep money that you have found & 0.71 & 0.04 & 0.18 \\
\hline Lying in your own interest & 0.64 & 0.19 & 0.24 \\
\hline Cheating on tax if you have the chance & 0.60 & 0.27 & 0.15 \\
\hline Avoid a fare on public transport & 0.56 & 0.34 & 0.00 \\
\hline $\begin{array}{l}\text { Claim government benefits that you are not } \\
\text { entitled to }\end{array}$ & 0.50 & 0.28 & 0.00 \\
\hline Driving under the influence of alcohol & 0.15 & 0.69 & 0.11 \\
\hline $\begin{array}{l}\text { Taking and driving away a car belonging to } \\
\text { someone else }\end{array}$ & 0.21 & 0.68 & 0.00 \\
\hline Throw away litter in a public place & 0.11 & 0.65 & 0.00 \\
\hline Political assassinations & 0.00 & 0.60 & 0.16 \\
\hline $\begin{array}{l}\text { Threatening workers who refuse to join a } \\
\text { strike }\end{array}$ & 0.00 & 0.59 & 0.11 \\
\hline Buy something you knew was stolen & 0.42 & 0.58 & 0.12 \\
\hline Taking the drug marijuana or hashish & 0.16 & 0.57 & 0.33 \\
\hline $\begin{array}{l}\text { Someone accepting a bribe in the course of } \\
\text { their duties }\end{array}$ & 0.32 & 0.56 & 0.11 \\
\hline Hit car - No report & 0.40 & 0.46 & 0.00 \\
\hline Fight with the police & 0.26 & 0.42 & 0.35 \\
\hline Divorce & 0.17 & 0.00 & 0.76 \\
\hline Abortion & 0.00 & 0.00 & 0.75 \\
\hline Homosexuality & 0.00 & 0.16 & 0.73 \\
\hline Prostitution & 0.00 & 0.28 & 0.68 \\
\hline Euthanasia & 0.12 & 0.00 & 0.64 \\
\hline Suicide & 0.00 & 0.35 & 0.60 \\
\hline Sex under age & 0.29 & 0.28 & 0.49 \\
\hline Married and have affair & 0.37 & 0.25 & 0.44 \\
\hline
\end{tabular}

\section{Independent Variables}

We rely on measures widely used in the sociology literature to measure the social institutions investigated in this study. The majority of measures use data from 1990, the year of the World Values Study Group's (1994) survey, with the exception of the percentage of government expenditures, based on 1989 data, and some country data on religiosity, which was only available for 1995 . See the Appendix for the list of countries and sample sizes.

The degree of capitalism or socialism (i.e., degree of governmental intervention and welfare state) was operationalized by central government expenditures expressed as a percentage of the gross domestic product. We reasoned that socialist countries would have a higher percentage of central government expenditures to reflect a higher level of governmental intervention, consistent 
with Olsen (1991). Data on government expenditures were collected from the United Nations Statistical Yearbook (United Nations 1992).

We assessed the degree of economic development by the general energy use (in mega tons of coal), similar to the measure used by Smits, Ulttee, and Lammers (1997). The indicator is accepted as a reflection of the level of development because more industrialized countries consume more energy. Data were collected from the United Nations Statistical Yearbook (United Nations 1992) and the World Bank World Development Indicators (World Bank 1998).

The GINI index is used to measure levels of inequality. It indicates the extent to which the distribution of income among individuals or households within a country deviates from a perfectly equal distribution (World Bank 1998). The GINI is accepted as a composite index of the wealth distribution in any society-higher GINI scores indicate greater social inequality. The GINI index was collected from the World Bank World Development Indicators (World Bank 1998).

We used the percentage of people attending religious ceremonies (e.g., church service) weekly as an assessment of the dominance of religions in different societies. Such country-level data on religiosity was gathered as part of the World Values Survey using representative national samples of each nation's adult population. To obtain data for all 20 nations included in our analyses, we used data collected in the years 1990-1991 and 1995-1997, as the first round did not include all 27 nations.

Table 2 shows a matrix of correlations and sample statistics of the individual-level and country-level variables investigated in this study.

\section{Control Variables}

The extant literature shows that individual-level factors also play a role in determining tolerance toward socially sanctioned behaviors. To control for such individual-level effects, we use a number of individual-level variables provided in the original data set (World 
Table 2.

Descriptive Statistics and Correlations ${ }^{1}$

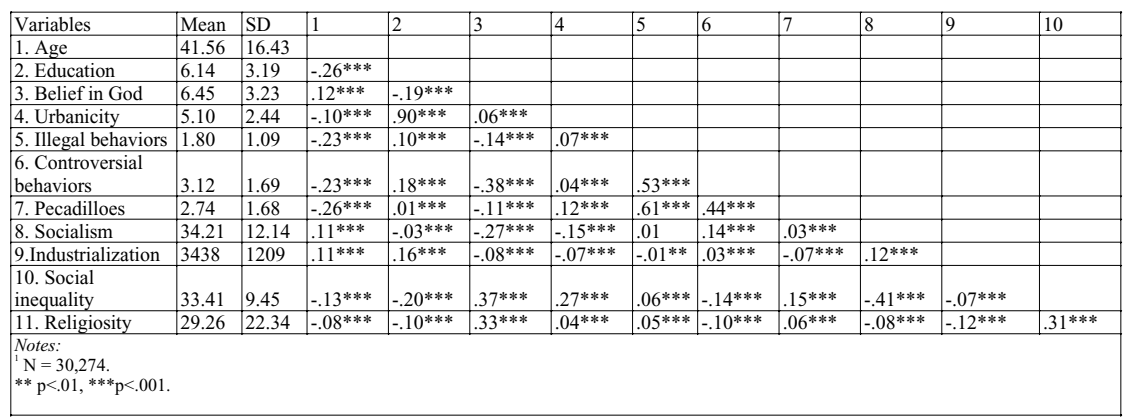

Values Survey). They include (1) age (measured in years), (2) education (years of education), (3) religion (1 to 10 scale to indicate the importance of God in their lives), and (4) urbanization (1 to 8 for size of town).

\section{Hierarchical Linear Modeling}

The design of the present study assumes that the institutional context of each country affects the behavioral intentions of individuals who live in the country. This contextual approach necessitates the demonstration of country-level effects above and beyond any individual factors that might potentially affect individuals' ability to justify socially sanctioned behaviors. Because traditional statistical techniques have been criticized heavily for their inadequacy in addressing some of the issues peculiar to cross-level studies (i.e., Bryk and Raudenbush 1989), we used Hierarchical Linear Modeling (HLM) (Bryk and Raudenbush 1989) as a more appropriate technique to assess cross-level relationships.

To assess the effects of social institutions on work values, the HLM model consisted of two levels. The level-1 model estimated the relationships between the dependent variables and individual-level controls. The level-2 model was an intercept-asoutcome model with level-1 covariates. In this model, the intercepts of separate individual-level regressions by country of justifications of sanctioned behaviors on the control variables became the country-level dependent measures for equations using social institutions 
as independent variables. Intercept-as-outcome models are used when the interest is in main effects of context variables on the dependent variable. The $t$-tests for $\gamma_{01}$ parameters produced in the level-2 analysis provided the tests of our hypotheses research questions. They show the effects of nation-level variables on justifications of unethical behaviors controlling for individual differences.

\section{RESULTS}

Table 3 shows the results of the HML analysis. As documented, the results provide evidence that all four social institutions investigated have significant effects on individuals' justification of socially sanctioned behaviors. It is important to note that these relationships are statistically significant above and beyond the expected influence of the important individual-level control variables included.

The results document a significant positive influence of the degree of socialism on the justification of all three types of behaviors, thus rejecting hypothesis 1 . As expected, the level of industrialization of countries was positively related to the individuals' justification of socially sanctioned behaviors, thus supporting hypothesis 2 . Social inequality, like degree of socialism, influences

Table 3. Results of the Hierarchical Linear Modeling Analysis Predicting Individuals' Ability to Justify Socially Sanctioned Behaviors

\begin{tabular}{|l|l|l|l|}
\hline & $\begin{array}{l}\text { Illegal } \\
\text { Behavior }\end{array}$ & $\begin{array}{l}\text { Controversial } \\
\text { Behavior }\end{array}$ & Peccadilloes \\
\hline & $\begin{array}{l}\text { Standardized } \\
\text { Coefficient }\end{array}$ & $\begin{array}{l}\text { Standardized } \\
\text { Coefficient }\end{array}$ & $\begin{array}{l}\text { Standardized } \\
\text { Coefficient }\end{array}$ \\
\hline \multicolumn{4}{|l|}{ Level 1 Variables (Individual Variables) } \\
\hline Age & $-.012^{* * *}$ & $-.01 * * *$ & $-.01 * * *$ \\
\hline Education & $0.003^{*}$ & $0.02^{* * *}$ & -.002 \\
\hline Importance of God & $-.005^{* *}$ & $-.02^{* *}$ & $-.004^{* *}$ \\
\hline Urbanicity & $0.018^{* *}$ & $0.04^{* * *}$ & $0.034^{* * *}$ \\
\hline Level 2 Variables (Social Institutions) \\
\hline Socialism & $0.04^{* * *}$ & $0.10^{* * *}$ & $0.10^{* * *}$ \\
\hline Industrialization & $0.02^{* * *}$ & $0.16^{* * *}$ & $0.01 *$ \\
\hline Social Inequality & $0.08^{* * *}$ & $-0.02^{* *}$ & $0.19 * * *$ \\
\hline Religiosity & $0.05^{* * *}$ & $-0.05^{* * *}$ & 0.00 \\
\hline$* \mathrm{p}<.1, * * \mathrm{p}<.01, * * * \mathrm{p}<.001$. & \\
\hline
\end{tabular}


individuals' justification differently depending on their type. Our results show a positive influence on tolerance for both illegal behaviors and peccadilloes, thus supporting our hypothesis 3 , but also a negative influence on the justification of controversial behaviors, contradicting hypothesis 3 . Through hypothesis 4 , we proposed that religion is negatively related to justification of socially sanctioned behaviors. The results provide only partial support for this hypothesis. Religiosity shows a negative relationship with justification of controversial behaviors. However, the results show also a positive association with individuals' justification of illegal behaviors while showing no significant association with peccadilloes.

\section{DISCUSSION}

\section{Sanctioned Behaviors}

We have conceptually distinguished two categories of sanctioned behaviors: controversial but mostly legal behaviors such as abortion and suicide as well as illegal behaviors such as accepting bribes or buying stolen goods. The empirical evidence from our factor analyses of the twenty-four items on sanctioned activities included in the World Values Survey document three classes of sanctioned behaviors. While controversial behaviors loaded on one factor, behaviors mostly forbidden by law are divided in two separate factors, which we term peccadilloes (including illegal behaviors that people may perceive as less serious such as avoiding transport fees or cheating on taxes) and illegal behaviors (including assassinations and drunk driving).

As our factor analyses controlling for country effects demonstrate, this factor structure is common to the 27 countries studied, as country has no significant influence on the factor loadings. This homogeneous cross-cultural classification of sanctioned behaviors provides some support for the notion of universalism (Kohlberg 1984) of value sets across countries.

While this three-factor solution underscores a clustering of sanctioned behaviors, it demonstrates that controversial behaviors, peccadilloes, and illegal behaviors are not, as assumed in the conceptual part of the paper, different grades on a uni-dimensional 
scale of sanctioned behaviors. Instead, our findings point to the existence of three distinct dimensions, or categories, of sanctioned behaviors, that are fairly independent of each other. This multidimensionality may offer a key to the somewhat heterogeneous findings with regard to the influence of the social institutions on these three types of socially sanctioned behaviors.

\section{Control Variables}

Regarding our control variable age, and consistent with previous results, age was found to have a negative association with our categories of sanctioned behaviors (Barnett and Karson 1989; Harris 1990). Older people tend to have a better understanding of the losses associated with controversial behaviors and peccadilloes and have stricter interpretations of ethical standards (Serwinek 1992) than younger respondents.

Results for importance of God had the expected negative relationship with our categories of sanctioned behaviors. Belief in God usually means a higher likelihood of belief in practices and values that parallel social norms. As such, it is logical that those who have stronger beliefs in God are less likely to justify illegal behaviors and peccadilloes (Singhapakdi et al. 2000).

Education level was positively related only to justification of controversial behaviors and illegal behaviors. The more educated an individual, the more the person is likely to justify our categorization of controversial behaviors such as abortion, homosexuality, and prostitution. Education can provide the means for individuals to cognitively process and justify behaviors traditionally sanctioned by society, but nevertheless acceptable.

In contrast to the non-findings of Osgood et al. (1996), urbanization was positively related to the justification of sanctioned behaviors. The larger the size of the city one lives in, the more likely that individuals justify socially sanctioned behaviors.

\section{Social Institutions}

Contrary to our hypothesis, the results from the cross-level analysis show that the economic system (degree of socialism) is negatively 
related to all three dimensions of sanctioned behaviors. It appears that the arguments derived from the literature on the effect of capitalistic systems on socially sanctioned behaviors do not hold true.

Although surprising, our results seem consistent with some of the major changes occurring in socialist countries. Many socialistic countries, especially the former communist countries, have undergone purposeful institutional changes, moving their economies to more of a market orientation (Nee 1989). In such cases, although the government is still heavily involved in the economy, there are deliberate attempts to infuse the economy with doses of entrepreneurial ventures and incentives for private profit (Whitley and Czaban 1998). As such, the traditional view of socialist societies being more concerned with the collective or common good (Ralston et al. 1997) may be waning. Consider, for example, the case of China where the Maoist doctrine of self-sacrifice and collective interest has been replaced by Deng's economic reform slogan "to get rich is glorious." Such transformations can potentially mean that people's actions are more guided by self-interest, thereby justifying the breaking of social norms and controversial behaviors. Furthermore, while socialistic societies provide security and stability to its members, they also impose narrow constraints on individual choices (Ingram and Clay 2000) with regard to selfdetermination and self-actualization. Individuals striving to actualize their personal objectives may find it very difficult to do so within the narrow frameworks of socialistic rules and are therefore tempted to "cut corners" by justifying peccadilloes or even illegal acts and confront society (and its perceived narrow norms) by engaging in controversial behaviors.

According to hypothesis 2 there is a positive relationship between a country's level of industrialization and individuals' level of justification of sanctioned behaviors. The findings from this research support this notion for all three dimensions of sanctioned behavior. The diminishing family structure (Carnoy 1999), materialist (Inglehart et al. 1998) and achievement orientations (Blau and Duncan 1967) may all promote justification of sanctioned behaviors as a way of coping with realities of life in an industrialized society. 


\section{Social Inequality}

Like the degree of socialism, social inequality shows different influences on the three types of sanctioned behaviors. Illegal behaviors and peccadilloes are positively influenced, thereby lending support to our hypothesis seeing social inequality as a driver for individuals' justification of socially sanctioned behaviors. However, it appears that the arguments presented for this hypothesis hold true only for behaviors sanctioned by law, as social inequality shows a negative influence on the justification of controversial behaviors. Thus, people in countries of high social inequality find it harder to justify behaviors such as divorce, abortion, or suicide.

A likely explanation for our unexpected findings of individuals in countries with less social inequality justifying more controversial behaviors may be the role of education and opportunity. In countries with less social inequality, individuals have greater opportunity to become educated. Education opens the mind to alternatives, change, and freedom of ideas, which often means deference to traditional social constraints. Birth control and abortion become viable alternatives to having children. Divorce and alternative family and lifestyles are no longer considered taboo along the way to economic and social achievement.

However, in countries with higher levels of social inequality, the lack of social mobility and exploitation from the elite may strengthen the reliance on strong family, community support and thus have a strong desire to preserve traditional values.

Also, the lack of educational opportunities typical in places of high social inequality, may prevent individuals from being exposed to the potential information that can allow one to cognitively process, accept, and question controversial behavior and alternative social patterns.

\section{Religion}

As a social institution, religion was argued to have a negative impact on the justification of sanctioned behavior. Our results, however, are mixed. Country level religiosity is negatively related to controver- 
sial behavior and positively related to illegal behavior, with no significant influence on peccadilloes. This finding is particularly interesting in light of the individual-level control variable "Importance of God," which demonstrates a clearly negative impact on all three kinds of sanctioned behavior, and thus lends some support for religion as a factor decreasing individuals' justification of socially sanctioned behavior.

Hence, apart from the hypothesized negative influence on justification of controversial behavior, religiosity has a definite positive contextual impact, above and beyond individual-level explanations for justify illegal behavior (Kelley and de Graaf 1997). Such results are peculiarly intriguing and we can only speculate on their nature. Perhaps, as argued by modernization theorists, as nations become more modern, their religious beliefs decline. Thus although church attendance is high, it is possible that religious beliefs are declining. Indeed, it seems plausible to argue that individuals in countries with high levels of religiosity face strong pressures to go to church, but may not adhere entirely to the religious beliefs. In addition, it is possible that with modernization, the traditional strict religious guidelines and beliefs are being relaxed to adapt to current times. Such changes imply that religious teachings are not addressing sanctioned behavior as was the case in the past. Or perhaps, with the realities of today's harshly competitive life, people in more religious countries are having difficulty living in the confines of religious beliefs and are reacting by justifying illegal behaviors and peccadilloes.

\section{CONCLUSION}

Despite the encouraging findings, some limitations are worth noting. First, all individual measures were obtained as part of the World Values Survey (World Values Study Group 1994). Although this survey provided the benefit of extensive cross-national data, the research expertise of the data-collection teams varied from country to country. This might have affected the quality of the data collected. Second, because we relied on secondary data, we had no control over the construction of our measures. However, we did take 
the necessary measures to provide discriminant validation of our measure. Finally, our measures were justifiability of behaviors, not actual behaviors. Although individuals' justification of certain actions provides a good indicator of behavioral intentions should the situation arise, our results should be viewed in that light.

Despite the limitations, this study makes some important contributions to the literature of sanctioned behavior. This study involved the proposal and testing of an innovative model based on social institutions through the comparisons of representative samples across 27 countries involving 32,374 individuals and should be evaluated accordingly. The results show that social institutions have significant effects on individuals, even after controlling for individual factors. In addition, despite the repeated pleas by cross-level researchers to use appropriate statistical methods, most studies rely on traditional error-prone regression analysis. We go beyond traditional regression analysis and use Hierarchical Linear Modeling, a technique that is widely accepted and used to test such cross-level relationships. As such, we consider our results to be robust.

Our findings point to the importance of further research in this area. First, the results of the factor analyses on the sanctioned behaviors resulting in three dimensions coupled with the HLM findings of quite different effects of the social institutions on the different types of sanctioned behavior highlights the importance of more fine-grained models. Second, as this study established a link between social institutions on the country level and individuals' justification of sanctioned behavior, additional empirical enquiry using current data in more and other countries is needed to further test our results. Third, future research is required to clarify the somewhat surprising influence of religion. The explanations for hypotheses-contradicting results provided above as well as other possible explanations should be developed and tested. 


\section{Appendix}

\section{Countries and Sample Sizes}

\begin{tabular}{|l|r|}
\hline Country & $\begin{array}{l}\text { Sample } \\
\text { Size }\end{array}$ \\
\hline 1. Argentina & 753 \\
\hline 2. Austria & 1315 \\
\hline 3. Belgium & 1948 \\
\hline 4. Brazil & 1671 \\
\hline 5. Britain & 1274 \\
\hline 6. Bulgaria & 824 \\
\hline 7. Canada & 1506 \\
\hline 8. Chile & 1319 \\
\hline 9. Finland & 455 \\
\hline 10. France & 854 \\
\hline 11. Hungary & 754 \\
\hline 12. Iceland & 604 \\
\hline 13. India & 2144 \\
\hline 14. Ireland & 888 \\
\hline 15. Italy & 1000 \\
\hline 16. Japan & 797 \\
\hline 17. Mexico & 1181 \\
\hline 18. Netherlands & 893 \\
\hline 19. Nigeria & 860 \\
\hline 20. Norway & 997 \\
\hline 21. Portugal & 1067 \\
\hline 22. Romania & 985 \\
\hline 23. Russia & 1187 \\
\hline 24. Spain & 3029 \\
\hline 25. Sweden & 821 \\
\hline 26. USA & 1625 \\
\hline 27. West Germany & 1383 \\
\hline Total & 32734 \\
\hline
\end{tabular}

\section{REFERENCE}

Adams, J. Stacy. 1965. "Towards an Understanding of Inequity." Journal of Abnormal and Social Psychology 67:422-436.

Baba, Marietta L. 1995. "Work and Technology in Modern Industry: The Creative Frontier". In Meanings of Working: Considerations for the Twenty-First Century, edited by F.C. Gamst. Albany, New York: State University of New York Press.

Barnett, J.H. and M.J. Karson. 1989. "Managers, Values, and Executive Decisions: An Exploration of the Role of Gender, Career Stage, Organizational Level, Function and the Managerial Decision Making." Journal of Business Ethics $8: 747-771$. 
Becker, Howard S. 1968. Outsiders: Studies in the sociology of deviance. Toronto: Free Press of Glencoe.

Berger, Peter L. and Thomas Luckmann. 1967. The Social Construction of Reality. New York: Doubleday.

Blau, Peter and Otis Duncan. 1967. The American Occupational Structure. New York:Wiley.

Blau, Judith R. and Peter M. Blau. 1982. "The Cost of Inequality: Metropolitan Structure and Violent Crime." American Sociological Review 47:114-129.

Braverman, Harry. 1974. Labor and Monopoly Capital: The Degradation of Work in the Twentieth Century. New York: Monthly Review Press.

Bryk, Anthony S. and Stephen W. Raudenbush. 1989. "Methodology for Cross-Level Organizational Research." Research in the Sociology of Organizations 7:233-273.

Carnoy, Martin. 1999. "The Family, Flexible Work and Social Cohesion at Risk.” International Labour Review 138:411-429.

Chiu, Catherine C.H., Kwok-fai Ting, Geoffrey K. Tso, and He Cai, He. 1998. "A Comparison of Occupational Values between Capitalist Hong Kong and Socialist Guangzhou." Economic Development and Cultural Change 46:749-770.

Diamond Jr., Arthur M. 1982. "Stable Values and Variable Constraints: The Sources of Behavioral and Cultural Differences." Journal of Business Ethics 1:49-58.

Esping-Anderson, G. 1990. The Three Worlds of Welfare Capitalism. Princeton: Princeton University Press.

Fararo, Thomas J. and Skvoretz John. 1986. "Action and Institutions, Network and Function: The Cybernetic Concept of Social Structure." Sociological Forum 1:219-250.

Goodwin, Jenny and David D. Goodwin. 1999. "Ethical Judgments Across Cultures: A Comparison between Business Students from Malaysia and New Zealand." Journal of Business Ethics 18:267-281.

Harris, J.R. 1990. "Ethical Values of Individuals at Different Levels in the Organizational Hierarchy of a Single Firm." Journal of Business Ethics 9:741-750.

Hofstede, Geert. 1980. Culture's Consequences. Beverly Hills, CA: 
Sage Publications.

Inglehart, Ronald, Miguel Basañez, and Alejandro Moreno. 1998. Human values and Beliefs: A Cross-Cultural Sourcebook. Ann Arbor: University of Michigan Press.

Ingram, Paul and Karen Clay. 2000. "The Choice-WithinConstraints New Institutionalism and Implications for Sociology." Annual Review of Sociology 26:525-546.

Jepperson, Ronald L. 1991. "Institutions, Institutional Effects, and Institutionalism." In The New Institutionalism in Organizational Analysis, edited by W.W. Powell and P.J. DiMaggio. Chicago: University of Chicago Press.

Kelley, Jonathan and Nan D. de Graaf. 1997. "National Context, Parent Socialization, and Religious Beliefs: Results from 15 Nations." American Sociological Review 62: 639-659.

Kerr, C., F.H. Harbison, J.T. Dunlop, and C.A. Myers [1960]1996. "Industrialism and Industrial Man." International Labor Review 135:383-392.

Knutsen, O. 1995. . "Left-Right Materialist Value Orientations." In The Impact of Values, edited by J.W.Van Deth and E. Scarbrough. New York: Oxford University Press.

Kohn, Melvin L., Kazimierz M. Slomczynski, Krystyna Janicka, and Valeri Khmelko. 1997. "Social Structure and Personality under Conditions of Radical Change: A Comparative Analysis of Poland and Ukraine." American Sociological Review 62:614-638.

Kohlberg, Lawrence. 1984. Philosophy of Moral Development. New York: Harper and Row.

Lewis, Michael. 1978. The Culture of Inequality. New York: New American Library.

Marx, Karl. 1936. Capital. New York: The Modern Library.

Mead, George H. 1972. Mind, Self, and Society. Chicago: University of Chicago Press.

Merton, Robert K. 1938. Social Theory and Social Structure. New York: Free Press.

Messner, Steven F. and Richard Rosenfeld. 1994. Crime and the American Dream. New York: Wadsworth.

Nee, Victor. 1989. "A Theory of Market Transition." American 
Sociological Review 54:66-81.

Olsen, Marvin E. 1991. Societal Dynamics: Exploring Macrosociology. Englewood Cliffs, NJ: Prentice-Hall.

Osgood, D.Wayne, Janet K. Wilson, Patrick M. O’Maley, Jerald G. Bachman, and Loyd Johnston. 1996. "Routine Activities and Individual Deviant Behavior." American Sociological Review 61:635-647.

Parish, William L. 1984. Urban Life in Contemporary China. Chicago, Il: University of Chicago Press.

Ralston, David A., David H. Holt, Robert H. Terpstra, and Yu KaiCheng. 1997. "The Impact of National Culture and Economic Ideology on Managerial World Values: A Study of the United States, Russia, Japan, and China." Journal of International Business Studies 28(1):177-207.

Roberston, Chris and Paul A. Fadil. 1999. "Ethical Decision Making in Multinational Organizations: A Culture-Based Model." Journal of Business Ethics 19:385-392.

Rossides, Daniel W. 1990. Comparative Societies. Englewood Cliffs, NJ: Prentice-Hall.

Serwinek, P.J. 1992. "Demographic and Related Differences in Ethical Views among Small Businesses." Journal of Business Ethics 11:555-566.

Simon, Herbert A. 1957. Models of Man. New York: Wiley \& Sons. Singhapakdi, Anusorn, Janet K. Marta, Kumar C. Rallapalli, and C.P. Rao. 2000. "Toward an Understanding of Religiousness and Marketing Ethics: An Empirical Study." Journal of Business Ethics 27:305-319.

Smits, Jeroen, Wout Ultee, and Jan Lammers. 1997. "Educational Homogamy in 65 Countries: An Explanation in Openness using Country-Level Explanatory Variables." American Sociological Review 63:264-285.

Streeck, Wolfgang and Phillipe C. Schmitter. 1985. "Community, Market, State-and Associations? The Prospective Contribution of Interest Governance to Social Order." In Private Interest Government: Beyond Market and State, edited by Wolfgang Streeck, and Phillipe Schmitter. Beverly Hills, CA: Sage. 
Turner, Jonathan H. 1997. The Institutional Order. New York: Addison-Wesley Educational Publishers.

United Nations. 1992. Statistical Yearbook. New York: United NationsPublication.

Van Deth, J.W. 1995. “A Macro Setting for Micro Politics.” In The Impact of Values, edited by J.W.Van Deth and E. Scarbrough. New York: Oxford University Press.

Vieraitis, Lynne M. 2000. "Income Inequality, Poverty, and Violent Crime: A Review of the Empirical Evidence." Social Pathology 6:24-45.

Walder, Andrew G. 1992. "Property Rights and Stratification in Socialist Redistributive Economies." American Sociological Review 57:524-539.

Warhurst, Christopher. 1998 "Recognizing the Possible: The Organization and Control of a Socialist Labor Process." Administrative Science Quarterly 43:470-497.

Weber, Max. 1922. Gesammelte Aufsaetze zur Religionssoziologie. Tuebingen. J.C.B. Mohr (Paul Siebeck).

Whitley, Richard. 1994. "Dominant Forms of Economic Organizations in Market Economies.” Organization Studies 15:153-182.

Whitley, Richard and Laszlo Czaban. 1998. "Institutional Transformation and Enterprise Change in an Emergent Capitalist Economy: The Case of Hungary." Organization Studies, 19: 259-280.

Wood, Greg. 2000. "A Cross Cultural Comparison of the Contents of Codes of Ethics: USA, Canada, and Australia." Journal of Business Ethics 25:287-298.

World Bank. 1998. World Development Indicators. Washington, D.C.: World Bank.

World Values Study Group. 1994. World Values Survey, 1981-1984 and 1990-1993 (Computer file). Ann Arbor, MI: InterUniversity Consortium for Political and Social Research. 